\section{Marcos e Problemas da História da Televisão no Brasil}

\author{
Leticia Cantarela MATHEUS ${ }^{1}$
}

RIBEIRO, Ana Paula Goulart; SACRAMENTO, Igor; ROXO, Marco. História da televisão no Brasil. Do início aos dias de hoje. SP: Contexto, 2010, 347p.

\section{História da Televisão no Brasil}

Do início aos dias de hoje, como o nome diz, trata dos primórdios da televisão no Brasil, dividindo sua trajetória em décadas em seis partes, de 1950 até os anos 2000. A obra, porém, não se prende à ordem cronológi$\mathrm{ca}$, pois tanto aprofunda temas específicos quanto discute problemas e objetos relativos à televisão pertinentes a período mais largo, tais como as telenovelas, o telejornalismo e sua interpelação pela matriz popular, os formatos híbridos, a relação com outros meios, tais como o rádio e o cinema, a formação do público e o recente processo de digitalização. O leitor pode transitar pelas seis primeiras décadas de nossa relação como esse novo meio de se comunicar, analisando, junto com os autores, a experiência audiovisual televisiva no Brasil.

Organizado pelos professores Ana Paula Goulart Ribeiro, Igor Sacramento e Marco Roxo, a publicação reúne trabalhos de 15 pesquisadores, além da participação dos próprios organizadores em dois dos capítulos. Ao mesmo tempo em que fornece um panorama geral da História da Televisão, o livro abre várias frentes. Ele permite atualizar o leitor de modo rápido, pois mapeia diferentes vertentes de estudo e ainda fornece novas ideias e abordagens para pesquisadores dedicados ao tema.

Convergência, por exemplo, é uma boa chave de leitura. O conceito vai além do fator tecnológico, pois diz respeito ao que chamamos de convergência comunicacional (Matheus, 2011), o que reúne elementos técnicos, estéticos e imaginários. Pode-se dizer que as duas primeiras décadas, tratadas como fase experimental, representam um período de composição, inicialmente improvisada, de técnicas oriundas de outros meios, como do rádio

1 Docente na Faculdade de Comunicação Social da Universidade do Estado do Rio de Janeiro (Uerj). e do teatro, e, principalmente, de composição a partir de múltiplas matrizes estéticas.

Nos anos 1950, a presença deste novo objeto cultural - o aparelho de televisão - e da experiência inédita de assistir à TV vão exigir do público em formação um processo cheio de tensões. No capítulo "Imaginação televisual e os primórdios da TV no Brasil”, a professora Marialva Barbosa relata parte dessa tensão entre os muitos sentidos sobre o televisual, em construção nos primeiros tempos, por exemplo, na decepção do público diante da nova imagem de seus ídolos. Personagens que saíram da imaginação construída pela escuta do rádio e que ganham materialidade visual.

Naquele contexto, há uma alteração da experiência da fama. Na TV, ela é potencializada pela imagem, tornando as pessoas irreais, quase mágicas, uma cópia presumida da realidade. Baseado inicialmente num ideal intimidade, característica própria do meio radiofônico, o princípio da fama precisou ser reelaborado com a televisão. Ela amplia a experiência sensorial do público, que passa a usar dois sentidos. Assim, os personagens que povoavam a imaginação adquirem rostos perfeitamente visíveis e identificáveis, talvez mais do que na época da publicação de fotografias dos ídolos do rádio nas revistas impressas. Todo o sistema de imagens - imprensa e rádio - é reformulado em função da introdução de um novo meio, alterando os modos de ver e de imaginar.

Isso se dá porque um novo meio não surge do nada e não é introduzido em tabula rasa. Ele faz acompanhar e acompanha uma matriz cultural que lhe dá sentido, põe os sentidos em relação e altera as estruturas de percepção. (McLuhan, 1969) A introdução de um novo meio altera as bases culturais da sociedade onde ele foi inscrito, por isso a necessidade de pensar os modos de comunicação de maneira integrada, como faz Barbosa. A relação entre os meios não é de acréscimo, mas de transformação mútua, complementaridade e concorrência.

Técnicas do rádio, do teatro e do cinema foram apropriadas para viabilizar a arte na televisão, até que ela desenvolvesse linguagem própria. "As primeiras produções teleficcionais" trata das apropriações da radiodramaturgia. A autora, Cristina Brandão, conta como se deu o processo de convergência entre duas frentes artísticas o teatro e o cinema - e sua contribuição para as primeiras experiências do teleteatro, que abririam cominho para o futuro sucesso das telenovelas. A década da TV ao vivo 
marcou o início do financiamento publicitário, associado às peças teleteatrais. Naquele momento, a TV absorveu grande parte do elenco, dos técnicos e diretores teatrais, que passaram a atuar no palco televisionado por câmeras fixas em transmissão ao vivo. Para se ter uma ideia, o ator entrava em cena com várias camadas de roupas, e ia se despindo dos figurinos para as diferentes cenas no decorrer da gravação.

Depois da convergência técnica, os anos 1960 são o momento das convergências estéticas. É o início da massificação da televisão, com seu estabelecimento como indústria, que era até então um fenômeno muito mais experimental e elitista. Já começa a haver profissionais formados na TV, não apenas especialistas de outras áreas incorporados.

O terceiro capítulo, "A reconfiguração do público", de Alexandre Bergamo, fala da consolidação de um público voltado para a TV, não apenas de uma simples transposição de interesses formados em torno do rádio. Os moldes e ritmos de produção se estabilizam, inclusive com a criação da grade de programação, o que leva o aspecto comercial da TV a outro patamar de profissionalização, além de ordenar os hábitos dedicados à audiência televisiva. As famílias passam a organizar seu tempo em função da grade de programação, aumentando a intimidade com o novo veículo.

O capítulo é particularmente instigante e esclarecedor sobre a dinâmica social que a TV teve no Brasil, pois ela representou a junção, mas principalmente a arena de conflito, de diferentes vertentes estéticas e cargas simbólicas do rádio, do cinema e do teatro, que se confrontaram, e também se adaptaram em termos de técnicas dramatúrgicas, técnicas de produção - iluminação, som, sonoplastia, figurino, planos, enquadramentos etc -. A televisão acabou por incorporar características e valores dos outros meios. Naquele momento, a tensão entre os profissionais oriundos do rádio e do teatro se acirra em busca do que se poderia chamar de autonomia televisiva, mas também em função da disputa da TV como área de influência pelo rádio ou pelo teatro. A televisão se tornara campo de batalha entre esses profissionais, batalha essa que materializava, por sua vez, um debate de fundo sobre os rumos da TV, traduzidos em termos de "níveis culturais" e de uma aparente contradição em relação às definições sobre quem seria o público. Enquanto o teatro consagrado era tido como referência estética, ti- nha-se, entretanto, o público do rádio como referencial, reconhecido e confundido como "povo".

(...) a ideia de "povo" como "público" da dramaturgia de televisão nos anos 1950 e 1960 era, em certa medida, uma continuidade da ideia feita do "público" do rádio. Não se tratava, é importante destacar, do público do teatro. Tratava-se de um "povo" ora descrito por suas qualidades morais, portanto não intelectuais ou culturais, ora descrito como ingênuo.” (BERGAMO, 2010, p. 70)

Portanto, aquele foi um momento de tensão entre a perspectiva da arte e a perspectiva da mercadoria, ao mesmo tempo em que se disputavam os modos de apropriação, traduzidos no que se compreende comumente como o "perfil" do público.

No capítulo 4, "A MPB na Era da TV", Marcos Napolitano traz a contribuição da música na formação televisiva e também da importância da televisão na consolidação de um consumo musical de massa nos anos 1960, com o surgimento dos programas musicais voltados à juventude. Os fãs da Bossa Nova e da Jovem Guarda se dividiram entre os programas da TV Record O Fino da Bossa e Jovem Guarda, este apresentado por Erasmo Carlos, Wanderleia e Roberto Carlos.

A televisão brasileira passa por ajustes e redefinições na década de 1970, com o estabelecimento do chamado "padrão Globo de qualidade", discutido no quinto capítulo, "A renovação estética da TV", de Ana Paula Goulart Ribeiro e Igor Sacramento. Ganham proeminência sobre as concorrentes Tupi, Record e Rio, as TVs Excelsior e sobretudo a Globo, cujos principais programas jornalísticos surgiriam nessa década (Fantástico, Globo Repórter e Jornal Nacional). A consolidação da hegemonia da TV Globo se dá pelo aproveitamento da criação da Embratel, parte da política de integração nacional, num projeto de criação de uma programação em rede, o que se obtém com o Jornal Nacional, em 1969. É o boom dos shows de calouros, como do Chacrinha, de Silvio Santos e de Moacyr Franco e também da programação gravada, graças ao videotape. Ainda no final da década, em 1979, debate-se o papel social da TV. No capítulo "O programa Abertura e a épica de Glauber Rocha", Regina Mota analisa a experiência do programa 
inovador de Fernando Barbosa Lima, na TV Tupi, e a passagem de Glauber Rocha pela televisão.

A quarta parte, referente aos anos 1980, aborda o novo impulso na popularização da TV, com a fundação do SBT e a ascensão da juventude como classe consumidora. Em "A teledramaturgia juvenil brasileira", Marina Caminha analisa a renovação da cultura jovem na televisão, depois dos festivais dos anos 1960, desta vez com novelas e programas dedicados exclusivamente ao público juvenil, como o seriado Armação ilimitada, na TV Globo. Num momento de distensão política, o humor e o cômico refrescam a televisão e ajudam a criar uma nova perspectiva sobre a realidade.

Aquela foi a década de aproximação com o escatológico. "A volta do jornalismo mundo cão", de Marco Roxo, relata a tradição do sensacionalismo na TV e mostra a assunção da vertente popular no jornalismo naquele período, com o retorno de programas da linhagem do Aqui e Agora, que estreou na TV Tupi do Rio de Janeiro em 1979, sempre marcados pela crítica. O mesmo jornalismo que era usado para auferir credibilidade às emissoras sofria as críticas devido à aproximação com o sensacional. Em 1991, o SBT lança o telejornal Aqui Agora, com o radialista Gil Gomes como repórter. "O que incomodava no Aqui Agora era ao fato de ele ser jornalístico.” (ROXO, 2010, p. 189). O jornal, que trazia a espontaneidade e agilidade do rádio, "abalou o cenário televisivo", ameaçou a liderança da Globo no horário e fez com que o grotesco se espalhasse pela programação das demais emissoras, tanto em programas policiais quanto de auditório.

Ainda sobre o sucesso do SBT, Maria Celeste Mota explica, em "O moderno e popular na TV de Silvio Santos”, que a emissora foi capaz de aproveitar um duplo esvaziamento que a televisão sofreu depois do processo de "saneamento" da década anterior, pressionada pela intelectualidade e procurando legitimação entre as classes intelectuais. De um lado, havia uma brecha comercial referente ao mercado direcionado às classes $\mathrm{C}$ e D. De outro, um vazio no imaginário popular, depois que as emissoras passaram a buscar um novo padrão de qualidade, restando ao SBT resgatar e preservar esse tipo de programação popular que havia sobrado das outras emissoras. Esse movimento seria acentuado com a exibição de novelas mexicanas e com o investimento em pro- gramas de auditório como Domingo Legal, com Gugu Liberato, e Programa do Ratinho, com Carlos Massa.

A década de 1990 assiste ao esgotamento do modelo "global" e a televisão busca alternativas de conteúdo e linguagem. É o início também de novas plataformas interativas e o mercado de TV sofre o impacto do sistema a cabo, com a possibilidade de maior segmentação. No capítulo "A reconfiguração do mercado de televisão pré-digitalização", Valério Cruz Brittos e Denis Gerson Simões fornecem um panorama do mercado e criam uma discussão em torno da democratização ou não da TV no Brasil.

A necessidade de remodelam ficou evidente com o sucesso da novela Pantanal, da TV Manchete, como aborda Beatriz Becker no capítulo "O sucesso da telenovela Pantanal e as novas formas de ficção televisiva”. O tempo e os planos da telenovela flertavam com o cinema. Ela explorava o silêncio, tinha ritmo mais lento, com ênfase em grandes planos externos, nos quais o ambiente era o personagem principal. Pantanal levava o público sair da rotina, possuía um sentido de evasão e romance, após momentos excessivo realismo nas telenovelas.

No capítulo "Em Linha Direta com os novos padrões para o telejornalismo", Kleber Mendonça trata do início do processo de incorporação da interatividade a partir do modelo do programa policial Linha Direta e de novas formas de narrativa e objetivação da autoridade telejornalística. O tema é retomado no texto que encerra a coletânea, "A ficção televisiva no mercado digital", de Ana Silvia Médola e Léo Vitor Redondo, que apontam a necessidade de desenvolver a interatividade tanto como produto final quanto como estratégia de fidelização, como nos exemplos do Intercine, do Você decide, ou mesmo da novela Prova de Amor, na qual o público decidiu o rumo da narrativa. O texto trata da TV digital como aposta para novas formas de sociabilidade e novas práticas de consumo da dramaturgia. Ganha outra dimensão a pervazividade dos conteúdos, que migram de certas plataformas ou mesmo que podem ser exibidos simultaneamente. Os autores chegam à conclusão que a interatividade no Brasil ainda é muito controlada, sem que se entenda do que se trata realmente esta lógica, que pressupõe autonomia do usuário. Poucos programas na TV brasileira podem ser assistidos pela net e as emissoras ainda resistem a disponibilizar esses conteúdos na rede. 
Finalmente, os anos 2000 são das convergências tecnológicas e do início da produção transmidiática. "Cinema e televisão no contexto da transmediação", de Yvana Fechine e Alexandre Figueroa, fala dos processos de digitalização e de globalização que caminham juntos. A própria digitalização pode ser tratada como um marco histórico na trajetória televisiva. O capítulo tratada também da relação entre globalização da TV, como a distribuição de formatos como os realities shows, e segmentação relativa de mercado. Aborda principalmente a questão do profissional habilitado a transitar por diferentes meios. Os autores relatam o recente processo de reaproximação da TV com a produção cinematográfica e as várias modalidades de confluência desses mercados. Primeiro, por reprocessamento de produtos originalmente realizados para uma determinada mídia com versão para outra; por desdobramentos, isto é, como elemento de inspiração, matriz para outra mídia; criações originais em parceria comercial entre empresas que trabalham em diferentes mídias; e, finalmente, por agendamento, ou seja, quando o sucesso de um tipo de mercadoria numa certa mídia pressiona as demais a criarem produtos em torno do mesmo tema. Trânsito de produções entre cinema e TV foi capitaneado pela Globo Filmes, que aproveitou e foi responsável pela retomada do cinema nacional, embora não tenha começado com a produtora.

Esses últimos capítulos da obra são atravessados pelo conceito de transmídia, de Henry Jenkins (2008), fenômeno que tende a beneficiar grandes empresas com capital para realizar muitos negócios simultaneamente. Surge novamente a questão da pervasividade entre os vários meios e a superação de mútuas desconfianças, por exemplo, entre TV e cinema, em função da possibilidade de novos negócios.

\section{Referências}

JENKINS, Henry, Cultura da Convergência. SP: Aleph, 2008.

MATHEUS, Leticia C. Comunicação, tempo, história: tecendo o cotidiano em fios jornalísticos. RJ: Mauad-X, 2011.

McLUHAN, Marshall. Os meios de comunicação como extensões do homem. SP: Cultrix, 1969. 